\title{
Obstructive Sleep Apnea
}

National Cancer Institute

\section{Source}

National Cancer Institute. Obstructive Sleep Apnea. NCI Thesaurus. Code C116337.

Cessation of air flow during sleep due to upper airway obstruction. 